\title{
Customer Relationship Management in the Pharmaceutical Industry
}

\author{
Thomas Puschmann, Rainer Alt \\ Institute of Information Management \\ University of St. Gallen \\ St. Gallen, Switzerland \\ \{Prename.Surname\}@unisg.ch
}

\begin{abstract}
Customer centricity has long been a guiding principle for many businesses. However, it is usually limited to marketing existing products with as strong a customer focus as possible. Corporate strategy remains basically product-centered. Customers typically have a fractured view of an enterprise. Conversely, the enterprise has only a splintered view of the customer, determined by different customer contact points, as customer information is usually locked in departmental silos. This article argues that trends like electronic commerce drive the need for a more customer-centric view. Customer relationship management, which is built on an integrated view of the customer across the whole organization, is currently being discussed as an appropriate concept for achieving this. To illustrate the elements of the concept, a case study undertaken at a pharmaceutical company provides the necessary empirical evidence.
\end{abstract}

\section{Introduction}

The pharmaceutical industry is undergoing an enormous transformation process. The rising costs and increased complexity of the pharmaceutical network combined with the emergence of new business models on the Internet are putting the healthcare sector under enormous pressure. Traditionally this market has been dominated by a variety of organizations which in the past played clearly defined roles and were very closely intertwined with one another. The Internet is calling these roles more and more into question while giving rise to new intermediaries called healthcare portals. These portals connect all participants over a central Internet platform and simplify the information exchange between them (see Figure 1) [1].

Healthcare portals, defined as web-based information and communication platforms in the healthcare sector, provide value for both suppliers and customers of healthcare services: pharmaceutical companies, wholesalers, pharmacies, doctors and hospitals are able to optimize reciprocal business processes and to generate patient profiles through the use of such portals [2]. This enables them to offer individualized products and services. The devel- opment of patient-specific drugs is currently being discussed under the term human genome research. The decoding of genetic information will enable pharmaceutical companies to offer customized medicines for each individual patient.

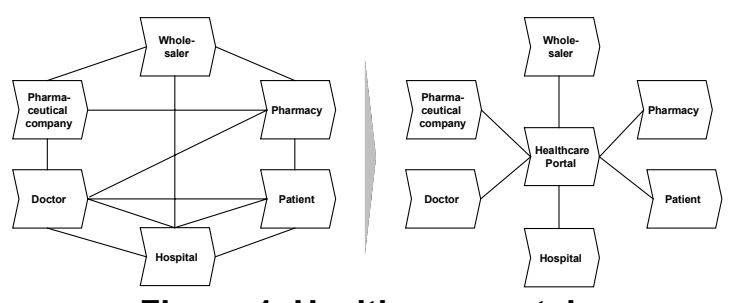

Figure 1. Healthcare portals

In this article we will outline how the customer relationship management (CRM) concept can be used to achieve better customer centricity in the pharmaceutical industry. We believe that CRM is not only a strategic concept, but is built on a clear understanding of the underlying processes and information systems. As a first step, we will therefore discuss the competitive situation which pharmaceutical companies face. Based on this, a case study will explain how a pharmaceutical company (referred to here as Pharma, Inc.) analyzed and implemented a CRM concept. This includes strategic considerations, the processes involved and the information systems used. In a subsequent chapter we will show how the alignment of internal processes and systems provides the foundation for healthcare portals. From this, the interplay of internal CRM processes and systems and healthcare portals is derived. Finally, chapter five draws some conclusions and summarizes the implications of the Internet for the pharmaceutical industry.

\section{Customer Relationship Management in the Pharmaceutical Industry}

\subsection{Challenges for Pharmaceutical Companies}

Although customer centricity has been propagated for years as a guiding principle for companies, product cen- 
tricity still dominates their marketing, sales and service activities. Customer orientation is mostly limited to support for customers needs during sales and after sales through customer-facing channels such as marketing, sales and service departments which are fast and accommodating but nevertheless isolated. Today's customers usually have more far-reaching requirements, however. Typically they are in the middle of a customer process, such as the curing of a disease (patients) or the possession of medical devices (doctors). Within this process they need a variety of products and services which they have to collect from different suppliers. Those vendors which bundle all the necessary services for a specific customer process via healthcare portals create an enormous added value (see Figure 2).

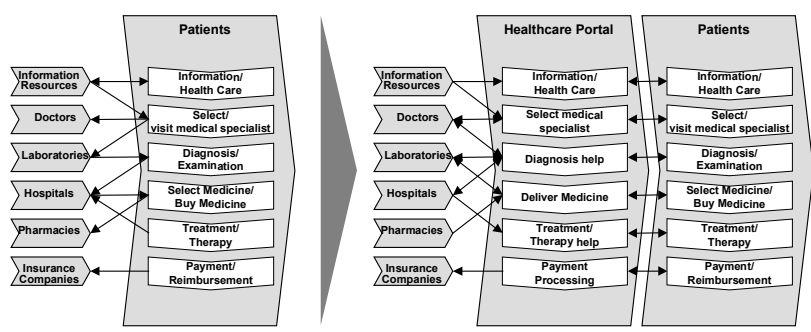

Figure 2. From product to customer centricity

Despite a high number of mergers and acquisitions the worldwide pharmaceutical industry is still very fragmented. The ten biggest pharmaceutical manufacturers cover only approximately 35 percent of the entire market volume [3]. No pharmaceutical company reaches a market share exceeding 5 percent. The fact that competitive advantage can rarely be achieved by product differentiation is forcing pharmaceutical companies to fundamentally rethink their selling strategies. The main determinants for this trend are:

- Cost pressure: Governments are putting pharmaceutical companies under pressure to reduce prices for drugs because of exploding costs in the healthcare environment.

- Regulation: The healthcare sector is extremely regulated. Every prescription drug, for example, is not released for publication until a clearly defined time frame has been established for clinical trials. Furthermore the European Union (EU) prohibits the marketing of prescription drugs to end-consumers. As in the USA where this law was reversed in 1997, attempts are being made to rescind this directive in the EU, too.

- Profitability: The development of new medicines is becoming more capital and time-intensive. In 1990 the development of a new marketable drug took at least 10 to 15 years and involved costs of an average US $\$ 500$ million [4]. Out of 10,000 basic substances only one or two medicines ever reach the market. Of these medicines less than 30 percent are profitable.
- Patent protection: A patent for a pharmaceutical product usually protects against imitations for 20 years. However, this time frame starts from the moment the patent is registered for the basic substance and not when the product becomes marketable. Actual patent protection therefore only covers a period of 8 to 10 years [3]. As soon as this protection expires cheaper generic products come onto the market. That is why a medicine has a maximum payback period of only 10 years. In addition, the net profits from these medicines also have to cover the costs of drugs that were stopped during clinical trials because of negative results.

The trends already mentioned clearly show that pharmaceutical companies have to move from product to customer centricity in order to remain competitive. In the past, most companies tried to reach the rank and file with the development of standard medicines such as Aspirin from Bayer. With pharmaceutical products becoming increasingly similar in terms of quality and effect, competitive advantage is moving more and more towards customer centricity.

\subsection{Customer Relationship Management at Pharma, Inc.}

Customer relationship management means increasing revenues and profitability by coordinating, consolidating and integrating all points of contact that enterprises have with their customers, which is what in effect integrates sales, marketing and service [5]. CRM focuses primarily on the marketing, sales and service processes:

- Marketing process: CRM supports the customer and the business itself with information on products, campaigns, customer profiling, etc.

- Sales process: CRM supports the customer with call center activities, product configuration information, etc.

- Service process: CRM supports the customer with problem analysis, handling guarantees, etc.

The goal of CRM is the forming, care and usage of personal relationships with the most important customers. Schulze et al. define CRM as a customer-oriented management approach that is based on information systems which integrate the information required for the support of front-office processes in marketing, sales and service [6]. Applied to the case of Pharma, Inc. this means that all customer contact points can rely on the same information based on integrated information systems. An integrated view of the customer across all organization units is therefore critical in order to achieve an efficient CRM concept [7].

Pharma, Inc., which is a top-ten multinational pharmaceutical company based in Switzerland, is faced with the following questions within the context of CRM: 
- What kind of healthcare portals already exist and what will be their role in the future?

- What does a globally integrated CRM architecture look like?

- How do CRM and healthcare portals interact and how can Pharma, Inc. position itself in this market?

Pharma, Inc.'s current marketing, sales and service organization can be characterized by isolated customer channels (see Figure 3). Key account management takes care of big customers, such as hospitals, wholesalers and pharmacies, whereas territory management tries to influence what doctors prescribe. Finally, patients are primarily attended on demand by marketing departments with medical information. A new channel which is currently gaining considerable importance in the US in particular uses the Internet and allows direct interaction with customers through healthcare portals.

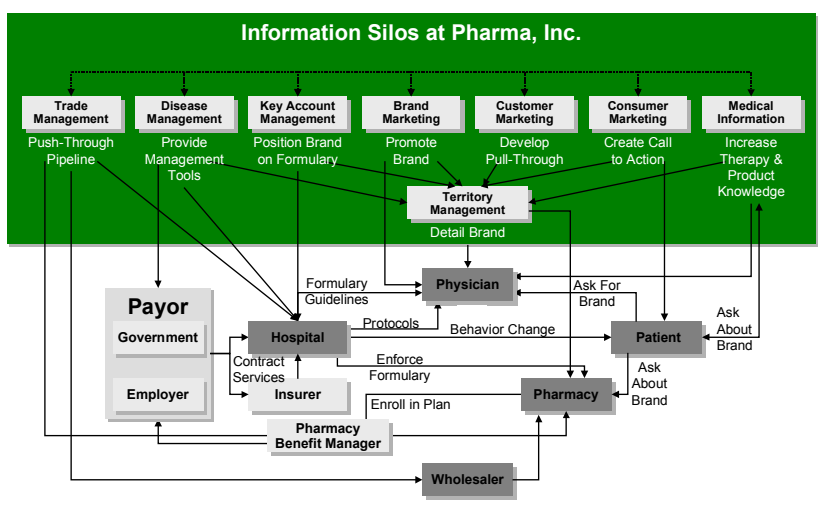

Figure 3. Isolated customer contact points

In contrast with other industries, such as the computer industry, marketing and access to patient information is restricted for pharmaceutical companies. The reasons for this is are governmental rules and the very complex structure of the healthcare system which separates pharmaceutical companies from patients through several intermediate stages in the supply chain, such as wholesalers and pharmacies. Compared with a computer manufacturer such as Dell Computer, a pharmaceutical company is not able to interact with the consumers (patients) of its products and to use this advantage in order to optimize customer relationships. Well-targeted customer profiling enables Dell to align its marketing, sales and service processes with the customers' processes. A prerequisite for this alignment is the bundling of customer information via Dell's website which integrates all the necessary data and makes it accessible for all employees who interact with customers. An essential critical success factor for an effective CRM strategy therefore lies in an integrated and homogeneous information systems architecture.

This means that an integrated CRM approach for the pharmaceutical industry has to consider both the marketing, sales and service processes which are provided by the marketing and service departments and the sales channels (key account management, territory management) as well as the underlying information systems which support these processes. The internal integration of customer-facing processes and systems is a prerequisite for pharmaceutical companies if they are to optimize customer relationships through the use of healthcare portals.

\section{Healthcare Portals}

\subsection{Process Portals}

Portals can be defined as web-based, personalized and integrated systems which offer access to applications, content and services [8]. If these portals support entire customer processes they are referred to as process portals [9]. Thus, as a vertical typology, healthcare portals transfer the traditional customer's healthcare process on the Internet. Electronic marketplaces, such as SAPmarketplace and MarketSite.net, primarily focus on the integration of reciprocally exchanged services and ignore the customer process orientation. Process portals on the other hand are characterized by the integration of services for one specific customer process. This view is provided by the concept of the Customer Resource Life Cycle (CRLC) which aims at supporting all customer needs at all stages [10]. This means that a customer is supported during the whole life cycle of possessing a product starting from information through buying and up to the disposal of that product. In order to provide all necessary services, process portals integrate their own services as well as services from cooperation partners. When comparing (horizontal) marketplaces with customer process-oriented (vertical) portals such as Dell's portal, the latter seem to be potentially stronger. The reason for this is that, compared with investment consultants, both marketplaces and stock exchanges have lower added value [8].

\subsection{Process Portals in Healthcare}

Figure 4 shows the customer's process of obtaining information about, buying and possessing medical devices and the accompanying services which are provided by Neforma.com [www.neoforma.com], a US healthcare portal. Neoforma.com offers the four core services Resources, Plan, Shop and Auction for doctors, hospitals and other organizations in the healthcare sector.

These core services are supported by a broad variety of processes that are offered via Neoforma.com's process portal. The "Resources" area offers personalized information and training services for customers. In the area "Plan" Neoforma.com provides a database for doctors which contains different methods of treatment for all kinds of syndromes. The same area contains a service for the 
equipment of specific departments, such as radiology, surgery or computer tomography. Within this area the buyer can browse through specific categories and sees all the necessary administrative and clinical equipment. These products can then be ordered via the "Shop" service. The auction service closes the customer resource life cycle by offering the possibility to tender used products.

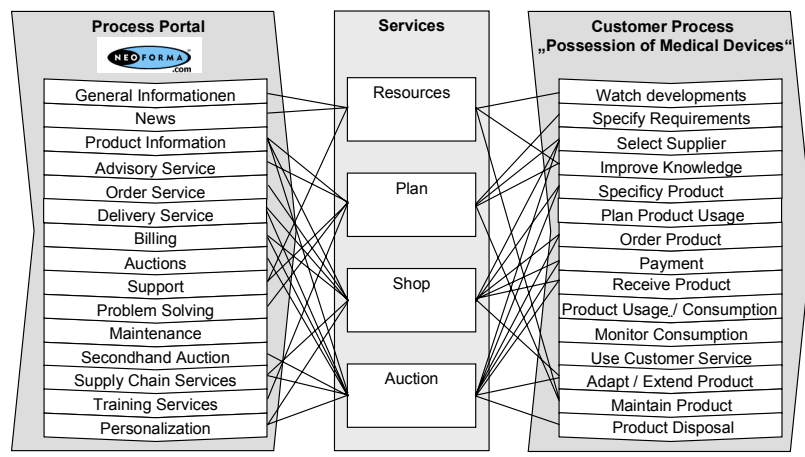

Figure 4. Services of Neoforma.com

Healthcare portals differ in the customer segment they support (business-to-business and business-to-consumer) and the services they provide. The emergence of portals which align their services very much towards the customer segments they serve is obvious because every customer segment in the pharmaceutical industry has its own specific process (see Figure 5). The customer process of a patient for example is characterized primarily by information, treatment and therapy whereas the process and the services needed by a doctor will focus on medical information, sales services for pharmaceuticals and medical devices, and training possibilities. Hospitals on the other hand are principally interested in integration services in order to streamline administrative and clinical processes between insurance companies medical specialists and their own departments.

We will apply the following classification of healthcare portals according to the services they offer:

- Information portals provide customers with information about diseases, medical products and services.

- Sales portals transfer traditional sales processes e.g. for prescription drugs and medical devices on the Internet.

- Integration portals connect the participants of the pharmaceutical network, such as insurance companies, doctors, hospitals and patients in order to reduce transaction costs.

\subsection{Information Portals}

Information portals offer information about diseases, symptoms, medicines, etc. for professional users and patients. A typical example of this category is the company
Intelihealth [www.intelihealth.com]. The company was founded in 1996 and is a joint venture of Aetna U.S. Healthcare and the John Hopkins University and Health System. The business model is exclusively built on advertising and other distribution channels such as Altavista, Compuserve and Pointcast who integrate health information in their own portals. Besides these, Intelihealth also uses traditional channels, such as television and radio. In 1999 Intelihealth won the Webby Award for the best health-related website on the Internet and was also given an award by Newsweek.

For private customers, the website offers information about different thematically structured areas, such as the allergy or cancer zone. Altogether the site provides information for about 200 syndromes. For specific questions not covered within the database, Intelihealth offers 35 "Ask the Experts FAQs", where patients can directly interact with doctors to discuss health-related topics. Discussion groups provide the possibility to talk with other patients affected. Besides this, Intelihealth offers information for professional users, such as nurses, doctors or pharmacists.

The major critical success factor for information portals is the quality, reliability and authenticity of the information provided. This is of utmost significance in the healthcare sector especially, where wrong or distorted information can have serious consequences. An additional requirement for information which is sent over open networks such as the Internet is privacy protection and security. In order to solve these problems, several European and US companies and other healthcare organizations founded the "Health on the Net Foundation" (HON). This non-profit organization is largely financed by Sun Microsystems, the Swiss Institute of Bioinformatics and the canton of Geneva. HON offers a trusted service which is based on a catalog of rules to ensure that medical information distributed via healthcare portals is authentic and reliable.

Information portals have a big influence on the doctorpatient relationship. The various health-related websites provide information on diseases and methods of treatment which is accessible to everyone. Traditionally, the dominant players in healthcare were the hospitals and doctors who look after the quality of medical services, and the health insurance schemes and governments who foot the bill. With the emergence of information portals the consumers of medical services are being given a powerful new tool. This instrument will cause the asymmetric distribution of power to move in the direction of a more balanced position.

\subsection{Sales Portals}

Providers who transfer traditional sales processes to the Internet are referred to as sales portals. In the case of 
healthcare portals these sites are also called online pharmacies. Companies such as Drugstore.com or PlanetRx.com are examples for this category of portal. Here we can differentiate between business-to-business portals like Neoforma.com for hospitals and doctors, and business-to-consumer portals for patients like CVS.com because of the different products and services needed for each customer segment.

An example of the process of purchasing prescription drugs via sales portals is provided by PlanetRx.com [www.planetrx.com] which was founded in 1999 and has had revenues of US \$ 52 million since October 1999. The company is headquartered in San Francisco and delivers products to the whole US market from its own distribution center in Memphis. In order to buy prescription drugs through PlanetRx.com's website, customers first have to enter their insurance number. After this, either the doctor or the patients themselves send the prescription to PlanetRx.com. In the latter case the company has to verify the validity of the prescription by contacting either the doctor or the appropriate pharmacy before fulfilling the order. For the payment process PlanetRx.com uses a very extensive network of health insurance companies in the USA. On the basis of the insurance coverage PlanetR.com finally bills the insurance company and sends another invoice with the percentage excess to the patient. In the future the company wants to support new technologies for drug prescription such as Allscripts, Inc. [www.allscripts.com] which offers a software called "TouchScript Personal Prescriber". This software substitutes paper-based prescriptions, allowing doctors to prescribe medicines online and automatically send them from the point-of-care to an online pharmacy.

The selling of prescription drugs in particular offers new possibilities for pharmaceutical manufacturers. In the same way that Amazon.com for example automatically pushes book suggestions to its customers on the basis of collected customer profiles, pharmaceutical companies now have a tool for collecting customer data and proactively offering individualized medicines. One example would be a search engine for medicines which provides information about the side-effects of the medicines and the after-effects of the diseases, too. Another example is DrKoop.com's Drug Checker [www.drkoop.com] which provides the user with information on the interaction of different drugs.

\subsection{Integration Portals}

The pharmaceutical supply chain involves a variety of participants who are in permanent interaction with one another. At the moment, most of these interactions are still paper-based. DeNelsky et al. estimate that in the USA more than 30 percent of the costs in healthcare are wasted due to system inefficiencies such as redundancies, unnec- essary treatments and the like [11]. Other countries have a similar proportion. The reasons for this are paper-based administrative processes, handwritten medical reports and diagnoses, etc. These costs can only be lowered if all processes between all participants are replaced by an integrated, electronic process. This is the service which companies aim to provide by offering integration portals (see Figure 5). For this reason they offer services such as multi-vendor product catalogs, electronic invoicing, electronic medical records and the like. These companies primarily offer integration services in three areas:

- Clinical integration: Doctors interact with other doctors, laboratories, pharmacies and insurance companies in order to exchange medical information, such as medical reports or letters of referral.

- Administrative integration: Hospitals and doctors interact with manufacturers of medical devices, pharmaceutical companies, etc., in order to exchange administrative information, such as orders or invoices.

- Financial integration: Insurance companies communicate with doctors, hospitals and pharmacies for accounting purposes.

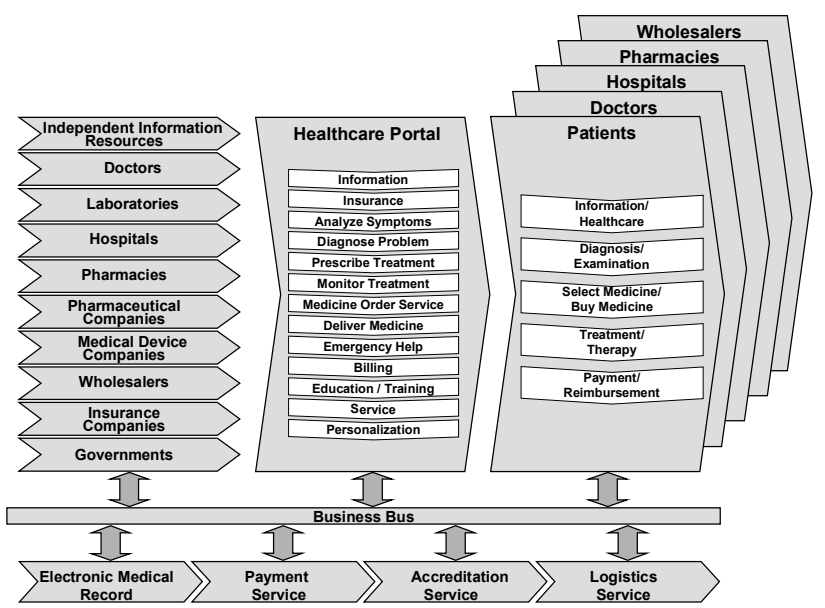

Figure 5. Architecture of healthcare portals

One of the major players in this market is WebMD [www.webmd.com] which was founded in 1999 following a merger between Healtheon which provided the information and transaction platform and WebMD which contributed the marketing strategy plus the strategic partnerships, for example with Medcast, a daily medical news channel. In recent months WebMD has pursued an aggressive expansion strategy acquiring OnHealth, Medical Manager, Careinsite, ENVOY and Kinetra. With revenues in excess of US \$ 104 million, the company is the undisputed market leader for integration services in the healthcare market.

WebMD offers services for several customer segments which include consumers as well as professional users such as doctors, laboratories, insurance companies, hos- 
pitals and pharmaceutical companies. A personal medical record allows patients to ensure that every doctor visited has access to the same information and doctors can avoid redundancies in treatments. Currently, WebMD only sells prescription drugs via the online pharmacy CVS.com which acts as a cooperation partner. Doctors have access to a broad variety of news, a medical library, a career center, medical education and administrative services for the procurement of medical devices and drug samples. Furthermore, doctors and hospitals have access to online laboratory test results. Doctors in particular appreciate the services of WebMD. In March 2000 approximately 18,000 doctors performed transactions via the portal, which means an increase of 400 percent within four months.

\section{Interplay of CRM and Healthcare Portals}

\subsection{Alignment of Sales Channels}

The implementation and use of healthcare portals assumes that a company knows its customers' needs and processes. So how can the customers of a pharmaceutical company be classified? According to Peppers and Rogers every industry's customer base can be characterized using the criteria customer valuation and customer needs (see Figure 6) [12]. Airline customers, for example, are characterized by a very steep value skew, with a small proportion of high-value customers accounting for the vast majority of the airline's profit. Once an airline customer is on board the aircraft, there is very little difference in the service needed. The customer's base of pharmacies, on the other hand, is very similar to that of a computer systems manufacturer. Dell's customers, for instance, show extreme variances in the products and services needed. Moreover, Dell knows its customers and can interact with them individually. By profiling Dell's customers through its website, the company is able to record and cater for the needs of each specific customer. Nowadays, because of the highly differentiated customer needs and customer valuations it is necessary to build up a one-to-one customer relationship.

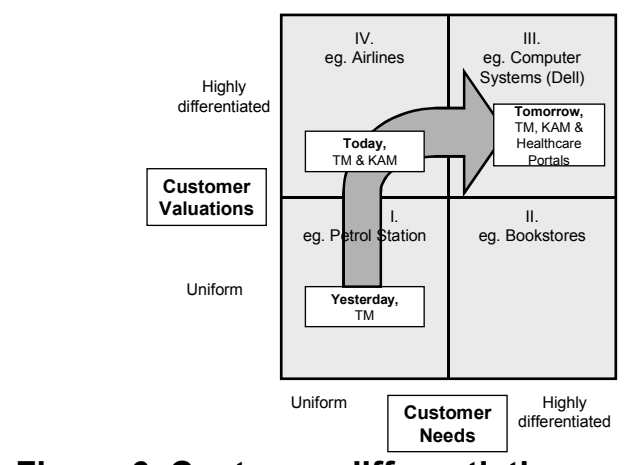

Figure 6. Customer differentiation matrix [12]
In contrast with other industries such as computer systems manufacturers, healthcare manufacturers differ widely in the customers they serve. Unlike a majority of other industries, the manufacturers that supply to the healthcare environment are usually restricted in their capacity to influence the final customer (the patient) to consume their goods within individual markets. That is why pharmaceutical companies do not know their end consumers [13]. In some countries several players intervene between the manufacturer of pharmaceutical products and the end-consumer. These factors have created a diverse, complex and fragmented environment across the global healthcare industry.

Bearing in mind that quadrant IV describes future customer needs and valuations, how can a pharmaceutical company move to the fourth quadrant? The natural strategy for a business that finds itself in quadrant III is to secure the continued loyalty of those most valuable customers who mean the most to the business [12]. For a pharmaceutical company this strategy translates into the development of an integrated key account management and field force structure for CRM with doctors, hospitals, wholesalers and pharmacies on the one hand and improved communication and interaction with the patients via healthcare portals on the other hand (see Figure 7).

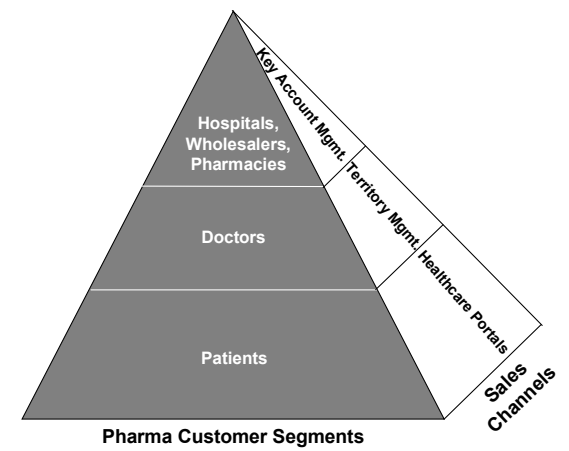

Figure 7. Pharmaceutical sales channels

Merck \& Co, for example, purchased Medco Containment Services, Inc., in 1993 for US \$ 6.6 billion, precisely in order to be able to create learning relationships with individual drug consumers and their physicians [14]. Relying on Medcos's comprehensive database of individual medical records, Merck can remind individuals on blood pressure medication, for instance, that their prescription is low. The company even works with pharmacists and physicians on behalf of specific patients to recommend pharmaceutical alternatives to surgery.

\subsection{Process Coordination}

Customer relationship management consists of three generic process categories: marketing, sales and service [15]. All of a company's customer contacts can be as- 
signed to one of these three front-office processes [16]. Back-office processes like procurement, research \& development and quality management, which are not directly involved in customer contacts, typically have interrelationships with CRM processes as well [17]. A very important example of the integration of front-office and back-office processes is product information concerning a specific medicine which is provided by research and development and must be available for marketing, sales and service, too. On the other hand, problems and suggestions from new clinical trials must be forwarded to research and development to eliminate side-effects.

In order to differentiate the three main processes marketing, sales and service it is useful to define which process addresses which target group and which output is generated at the end of each process. The marketing process generally targets the whole market. The sales process encompasses all activities which should lead to a contract with prospective buyers. Typically, activities within this process include expert advice and the distribution of samples. The sales process finally ends with a contract. All other customer contacts can be assigned to the service process which supports the customer with goods delivery, call centers, maintenance, etc.

These front-office processes provide the services for healthcare portals. From a company's point of view, the process portal provides the interface to the customer. With every contact, the customer utilizes services from the process portal. The CRM processes provide these services (see Figure 8). Every customer segment passes through its own customer process during the course of which the customer repeatedly interacts with the process portal which supports him through individualized services, such as product information and order services.

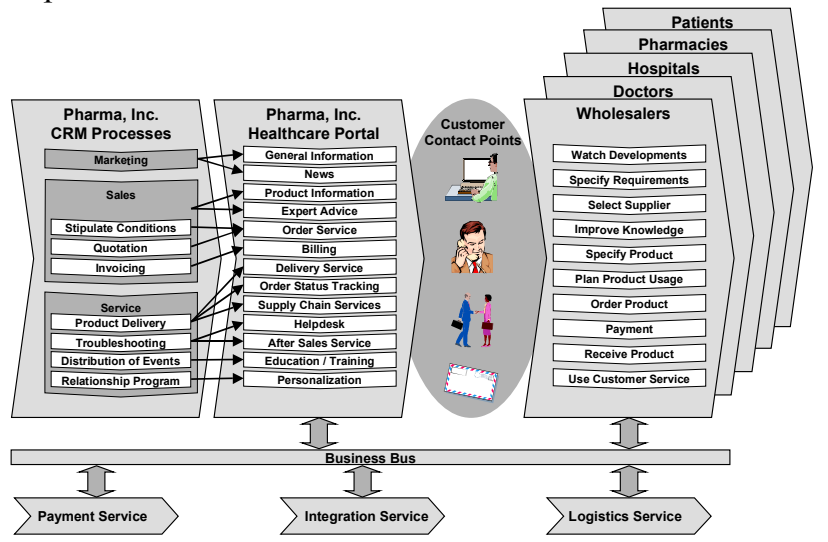

Figure 8. Interaction of CRM and portals

Highly standardized services, such as payment, logistics or integration services are sourced from specialized electronic service (eService) suppliers via the "business bus". The business bus is the term used to describe the totality of technical, applications and business standards on which software solutions, eServices, etc. are based [9]. An example of an integration eService in the healthcare sector is ShareNet [www.sharenet.org] which operates an EDI platform for processing electronic transactions (exchange of patient data, billings, etc.) This clearing center service lets participating companies exchange information without having to implement individual EDI links amongst themselves.

\subsection{Integration of Information Systems}

Process portals are not the only customer contact point. Personal contacts, telephone contacts, etc. are examples of other channels that a customer uses to interact with pharmaceutical companies. Fuelled by the evolving Web technology, most organizations have become extremely proficient at collecting vast amounts of data which are usually scattered across the enterprise in disparate formats. Leveraging this data to gain competitive advantage demands integration, most commonly between the back-office and the front-office. Pharmaceutical companies therefore not only have to align their internal processes but must also provide a consistent view of customer information across all organization units that interact with customers.

As such areas of the enterprise are usually under the control of different vendors' products, this ideally requires cross-market integration and collaboration such as that between SAP R/3 and CRM systems. Customer information is typically sourced from a variety of internal and external company employees. It is therefore critical that all this individually collected information can be consolidated and made available to all operatives, whether in the marketing department, key account management or the mobile sales force. That is why one critical success factor for leveraging the full benefits of CRM is the integration with the backend system(s). A comprehensive management of marketing, sales and service processes requires the integration of outward, interactive processes in the front-office with the inward, transaction-oriented processes in the back-office. Whereas ERP systems only aim at enhancing productivity and efficiency in a company's back-office, CRM systems intend to improve customer relationships in the front-office [17].

Today, Pharma, Inc.'s key account management and territory management use separate systems for the support of their marketing, sales and service processes. It is planned that these systems should be harmonized into one CRM system. Marketing is also supported by their own information systems. In order to coordinate campaigns with corresponding sales activities and customer visits it will become necessary to integrate those systems with the other front-office systems. Moreover, all transactionoriented and finance-related data, such as prices, orders and invoices are held within ERP systems. Another integration area is clinical trial applications. As an important 
quality indicator for medicines, this category of information is very useful for doctors and is typically stored in specific systems which are integrated with research and development applications as well. In order to provide the KAM and TM with appropriate information these applications must also be integrated into the CRM landscape.

An integrated customer information database ultimately builds the basis for all applications which access customer-oriented information. This encompasses all customer-related information and is based on the following categories:

- Customers: Name, address, phone, email, interests and position within the customer power structure, etc.

- Products: Positioning, prescription guidelines, clinical activities, availability, promotional activities, etc.

- Financials: Potentials, spend, sales (e.g. forecast, actual budget), etc.

- Activities: marketing campaigns, clinical trials, congresses, events, etc.

Figure 9 shows the application architecture which was developed at Pharma, Inc.

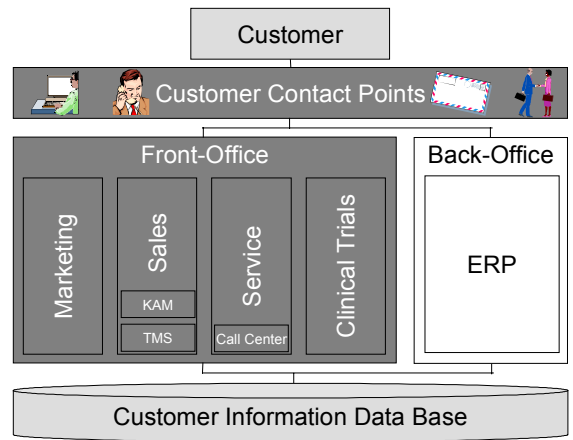

Figure 9. CRM application architecture

\section{Summary and Outlook}

Healthcare portals are revolutionizing customer relationships in the pharmaceutical industry. The cost pressure on public healthcare is calling the efficiency of traditional, isolated marketing, sales and service processes into question. Currently, productivity improvements in pharmaceutical companies' sales organizations through benchmarking and better market research data are leading to an adjustment of competitive advantage across the industry. Companies are still trying to compensate this homogeneity with an increase in medical representatives who try to influence doctors' prescription decisions, although the number of doctors remains constant.

This development is paving the way for a new kind of service integration through healthcare portals. These portals will have a lasting effect on the healthcare process and ultimately on the processes of pharmaceutical CRM processes, too. Healthcare portals are positioned as intermediaries between pharmaceutical companies, medical device companies, insurance companies, laboratories and governments on the one side and patients, doctors, hospitals, wholesalers and pharmacies on the other. The current differentiation between information, sales and integration portals will probably disappear in the near future and the portals will be developed into full process portals which support entire customers' processes, as the example of WebMD shows [18]. Critical mass is always a major critical success factor for such portals. As a consequence they will provide services for clinical, administrative and financial integration for more than just one customer segment.

The major benefit of healthcare portals for pharmaceutical companies will arise from the possibility of direct interaction with end-consumers and patients, which will offer a better analysis of customer needs and their transformation into the development of individualized products. The effect on the traditional marketing, sales and service channels of pharmaceutical companies could be drastic. In the USA about 175,000 doctors already use healthcare portals for accessing personalized general medical information as well as information about pharmaceutical products and services [19]. This instrument allows them to analyze clinical trials better and faster, or to order drug samples directly from the manufacturer. The growing use of electronic networks seems to be leading to a redefinition of pharmaceutical companies' CRM organization. The traditional sales organization therefore will have to be changed from a cost-intensive push to an efficient pull system. As a result doctors and pharmacists will increasingly satisfy their information needs via healthcare portals, only ordering those products which are styled exactly to suit the patients' needs and, even more importantly, which are what the patients who also use healthcare portals actually want.

This changing environment poses a new challenge for pharmaceutical companies and leads to the question of how a traditional pharmaceutical company like Pharma, Inc. can position itself in the healthcare portal market. Up to now only a few pharmaceutical companies have reacted and initiated portal projects. Generally speaking, we can distinguish between two main strategies: one is to found an own healthcare portal and the other is to take over or participate in an existing portal. Aventis, for example, which is a top-ten pharmaceutical company headquartered in Basel, Switzerland, is planning to establish an own portal whereas Glaxo Wellcome, based in Research Triangle Park, N.C., wants to participate in a neutral portal. However, the creation of portals by pharmaceutical companies would appear critical because customers may trust neutral portal providers more readily than those owned by pharmaceutical companies which might abuse customer profiles for their own business goals. The second strategy, i.e. the participation of pharmaceutical manufacturers in healthcare portals seems to be more probable. 


\section{References}

[1] Webb, T., The Role of the Internet in Healthcare, in: Nicholson, L. (ed.), The Internet and Healthcare, $2^{\text {nd }}$ edition, Health Administration Press, Chicago, 1999, pp. 11-31

[2] Kilbridge, P.M., Schneider, M., Implications of the Internet: The Physicians Perspective, in: Nicholson, L. (ed.), The Internet and Healthcare, $2^{\text {nd }}$ edition, Health Administration Press, Chicago, 1999, pp. 33-44

[3] Interpharma, Pharma Information Press Release September 22nd 1999, http://www.interpharma.ch/info/ wissens/pharmamarkt/GelbB99d.pdf, 15.09.2000.

[4] Pharma Industry Profile, http:/www.phrma.org/ publications/industry/profile99/chap2.html\#development, 15.09.2000

[5] Österle, H. Muther, A., "Electronic Customer Care", in: Wirtschaftsinformatik 40 (1998) 2, pp. 105-113

[6] Schulze, J., Bach, V., and Österle, H., "Customer Relationship Management: Konzept, Potentiale und methodische Einführung", in: HMD 37 (2000) 212, pp. 218 .

[7] Körner, V., Zimmermann, H.-D., Management of Customer Relationship in Business Media: Motivation for a New Approach, in: Klein, S., Gricar, J., Pucihar, A. (eds.), Global Networked Organizations, Proceedings of the $12^{\text {th }}$ Electronic Commerce Conference, Moderna Organizacija, Kranj, 1999, pp. 453-468.

[8] Österle, H., Geschäftsmodell des Informationszeitalters, in: Österle, H., Winter, R., Business Engineering, Springer, Berlin etc., 2000, pp. 40.

[9] Österle, H., Enterprise in the Information Age, in: Österle, H., Fleisch, E., Alt, R., Business Networking: Shaping Enterprise Relationships on the Internet, Springer, Berlin etc., 1999, pp. 17-54.

[10] Ives, B., Learmonth, G.P., The Information System as a Competitive Weapon, in: Communications of the ACM 27 (1984) 12, S. 1193-1201.
[11] DeNelsky, S., Haspel, Max. B., Lam, E., E-health II: Beyond the Business Plan, Credit Suisse First Boston, Oktober 1999.

[12] Peppers, D., Rogers, M., Enterprise One to One: Tools for Competing in the Interactive Age, Random House, New York, 1997.

[13] Wigglesworth, K., Zelcer, J., The Healthcare Supply Chain: Applying Best-Practice Remedies to the Healthcare Sector, in: Gattorna, J. (Ed.), Jones, T., Danks, A., Dhillon, Y., Holdforth, L., (Ass. Ed.), Strategic Supply Chain Alignment: Best Practice in Supply Chain Management, Gower, Vermont, 1998, pp. 572-587.

[14] Evans, P., Wurster, T.S., Blown to Bits: How the New Economics of Information Transforms Strategy, Harvard Business School Press, Boston, 2000.

[15] Schmid, R.E., Bach, V., Österle, H., Mit Customer Relationship Management zum Prozessportal, in: Bach, V., Österle, H., Customer Relationship Management in der Praxis, Springer, Berlin etc., 2000, pp. 3-55.

[16] ECCS, CRM Definitions: Defining customer relationship marketing and management, http://www.eccs. uk.com/crmdefinitions/define.asp, 15.09.2000.

[17] Kalakota, R., Robinson, M., E-Business: Roadmap for Success, Addison Wesley, Massachusetts etc., 1999.

[18] Arnold, D., Trends in Healthcare Information Technol$o g y$, in: Nicholson, L. (ed.), The Internet and Healthcare, $2^{\text {nd }}$ edition, Health Administration Press, Chicago, 1999, pp. 6376

[19] Roth, C.B., Healthcare Portale und Kundenprofile, in: Belz, C., Bussmann, W., Vertriebsszenarien 2005: Verkaufen im 21. Jahrhundert, Ueberreuter, Vienna, 2000, pp. 153156 